\title{
HAEMANGIOMA OF THE IRIS*
}

\author{
BY
}

\author{
H. B. STALLARD \\ London
}

PARSONS (1904) remarked in his classic book Pathology of the Eye that "haemangiomata of the iris are excessively rare". Indeed, only nine have been recorded in the literature, which were proved to be haemangioma on microscopic examination; these were recorded by Rodin (1929), Rochat (1941), Dekking (1951), Trujillo (1952), Reese (1963, 2 patients), and Ashton (1964, 3 patients, 1 of whom is the patient described in this paper who came under my care in 1962). In the textbooks, Samuels and Fuchs (1952) in Clinical Pathology of the Eye state that "haemangioma of the iris is practically never seen"; Hogan and Zimmerman (1962) in their book Ophthalmic Pathology comment that "haemangiomata of the iris have been observed clinically, are seldom excised, and glaucoma may follow recurrent haemorrhages into the anterior chamber"; and no mention is made of haemangioma of the iris in Wolff's book A Pathology of the Eye (1951).

The following case is reported because (1) recurrent haemorrhages into the anterior chamber and the increasing size of the haemangioma made its surgical removal necessary, and (2) the technique of partial iridectomy had to be such, that in withdrawing the affected sector of the iris from the anterior chamber and in excising it, the neoplasm did not start bleeding to embarrass the precision of the operation.

\section{Case Report}

A male lecturer, aged 57, had recurrent attacks of pain for nine months in the left eye and blurred vision after physical exertion. Fig. 1 shows a raised crimson-coloured neoplasm composed of dilated tortuous thin-walled blood vessels on the pupil margin at about 7 o'clock in the left eye. Vision in the left eye was 6/9. A diagnosis of haemangioma was made.

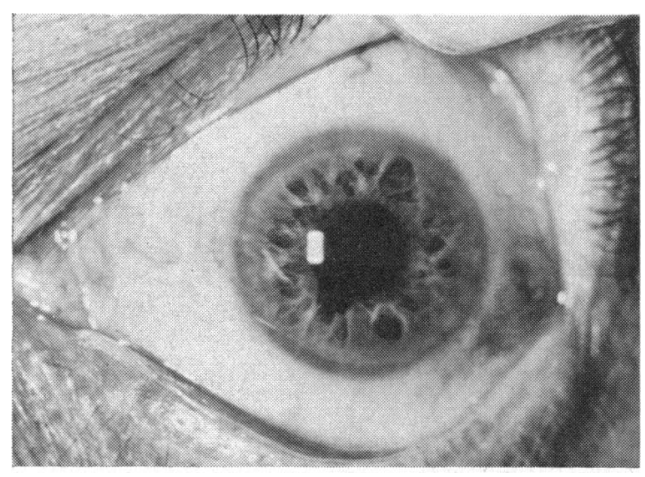

FIG. 1.-Haemangioma of the iris, lower nasal quadrant.

FIG. 2.-A fine diathermy coagulating needle was used to circumvallate the neoplasm.

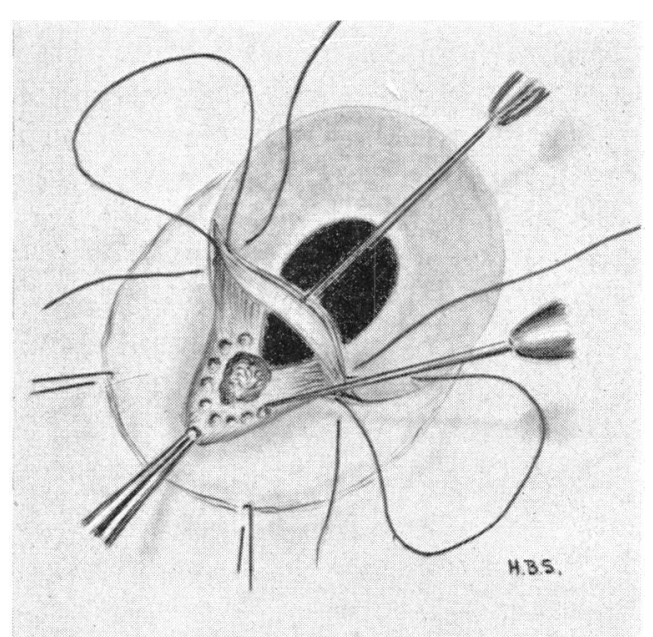

* Received for publication March 5, 1965. 
Operation.-As the afferent and efferent vessels which passed between the iris stroma and the neoplasm were dilated it seemed that their division by a cutting instrument might lead to embarrassing and possibly recurrent haemorrhage into the anterior chamber. It was decided to withdraw the lower nasal quadrant of the iris from the eye through an ab externo limbal incision sufficiently generous to lift the cornea well clear of contact with the neoplasm, which might cause it to bleed, and outside the eye to circumvallate the neoplasm with a fine diathermy coagulating needle (Fig. 2). The iris was then cut with de Weckers' scissors through the diathermized zone (Fig. 3) and there was no bleeding. The iris was replaced and the incision closed by tying the presection limbal sutures, and covering it with a conjunctival hood flap.

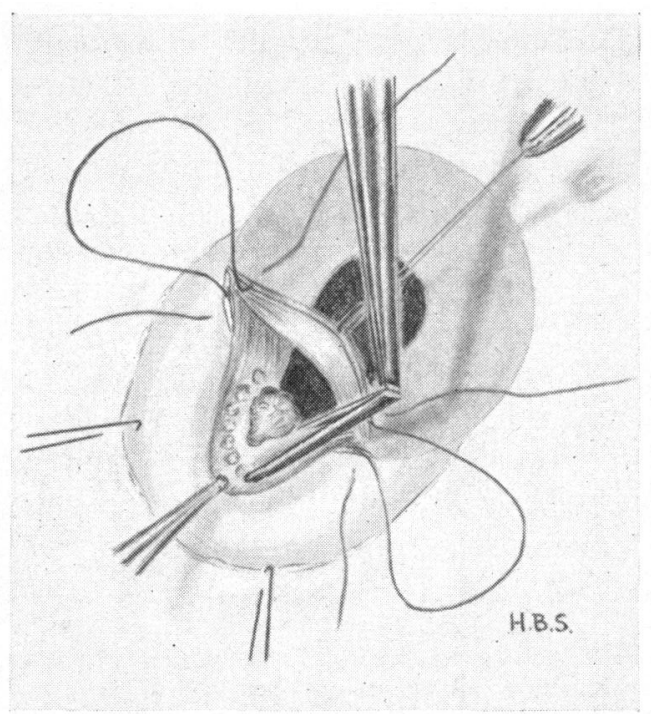

Fig. 3.-The iris cut with de Weckers' scissors through diathermized circumvallation.

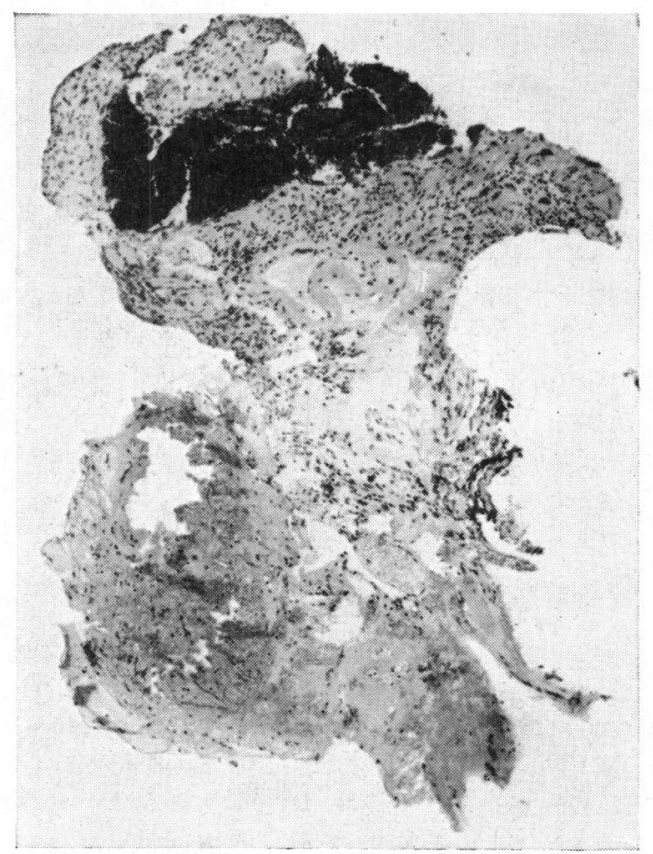

FIG. 4.-Section of the haemangioma.

The post-operative course was without any untoward event. The diagnosis was confirmed by section (Fig. 4).

Three years after operation the patient's vision remains $6 / 9$ and there has been no recurrence of the neoplasm or of haemorrhages into the anterior chamber.

I thank Mr. W. K. Smiley for his kindness in sending this patient to me, and for his follow-up notes. I thank also the Pathological Department and the Medical Illustration Department of the Institute of Ophthalmology for the photographs of the section and of the clinical appearance of the eye before operation.

Ashton, N. (1964). Brit. J. Ophthal., 48, 650.

\section{REFERENCES}

DeKKING, H. M. (1951). Ophthalmologica (Basel), $122,386$.

Hogan, M. J., and Zimmerman, L. E. (1962). Ophthalmic Pathology, 2nd ed. Saunders, Philadelphia.

Parsons, J. H. (1904). " "The Pathology of the Eye", vol. 1, pt. 1, p. 325. Hodder and Stoughton, London. ReESE, A. B. (1963). "Tumors of the Eye", 2nd ed., p. 402. Hoeber, New York.

Rochat, G. F. (1941). Ned. T. Geneesk., 85, 1130.

Rodin, F. H. (1929). Arch. Ophthal. (Chicago), $2,679$.

Samuels, B., and Fuchs, A. (1952). "Clinical Pathology of the Eye". Cassell, London.

Trujillo, F. R. (1952). Rev. bras. Oftal., 11, 65.

WolfF, E. (1951). "A Pathology of the Eye", 3rd ed. Lewis, London. 